J. Lake Sci. (湖泊科学 ), 2006, 18( 1 ):91-96

http:// www. jlakes. org. E-mail: jlakes@ niglas. ac.cn

(c) 2006 by Journal of Lake Sciences

\title{
东太湖水环境现状及保护对策"
}

白秀玲 ${ }^{1,2}$, 谷孝鸿 ${ }^{* * 1}$, 杨龙元 ${ }^{1}$

( 1 : 中科院南京地理与湖泊研究所, 南京 210008 )

(2:中国科学院研究生院, 北京 100039 )

摘 要: 根据 2002 年 4 月至 2003 年 4 月东太湖的水质监测结果, 分析了东太湖的水质现状、空间分布特征及变化趋势. 其中 $\mathrm{TN}$ 变化范围 $0.57-3.91 \mathrm{mg} / \mathrm{L}$, 平均值 $1.61 \mathrm{mg} / \mathrm{L}, \mathrm{NH}_{4}^{+}-\mathrm{N}$ 变化范围 $0.01-0.42 \mathrm{mg} / \mathrm{L}$, 平均值 $0.14 \mathrm{mg} / \mathrm{L}, \mathrm{NO}_{3}^{-}-\mathrm{N}^{-}$ 变化范围 $0.044-0.549 \mathrm{mg} / \mathrm{L}$, 平均值 $0.16 \mathrm{mg} / \mathrm{L}$, 而 TP 平均值为 $0.103 \mathrm{mg} / \mathrm{L}$, 与以前的调查结果相比, $\mathrm{TN} 、 \mathrm{TP}$ 和 $\mathrm{NH}_{4}^{+}-\mathrm{N}^{+}$ 均明显增加, $\mathrm{COD}_{\mathrm{Mn}}$ 有所下降, 水质状况总体较差, 但不同水域因其影响因子不同, 水质亦有明显差别, 湖心 区水质最好. 目前, 东太湖水体总体上处于中富营养状态, 部分湖区已达到富营养状态. 最后根据东太湖水环境的现状, 提出一些措施 和建议.

关键词: 水质; 变化; 保护; 东太湖

\section{Analyses on water quality and its protection in East Lake Taihu}

BAI Xiuling ${ }^{1,2}$, GU Xiaohong ${ }^{1} \&$ YANG Longyuan ${ }^{1}$

( 1: Nanjing Institute of Geography and Limnology, CAS, Najing 210008, P. R. China)

( 2: Graduate School, CAS, Beijing 100039, P. R. China)

Abstract: Based on the water quality investigation in East Lake Taihu from April 2002 to April 2003, a preliminary analysis was carried out on the water quality, its changes and the spatial difference in given districts. The mean value of the water quality parameters ranged as follows: TN, $0.57-3.91 \mathrm{mg} / \mathrm{L}$ with a mean value of $1.61 \mathrm{mg} / \mathrm{L}$; $\mathrm{NH}_{4}^{+}-\mathrm{N}, 0.01-0.42 \mathrm{mg} / \mathrm{L}(0.14 \mathrm{mg} / \mathrm{L}$ on the average $) ; \mathrm{NO}_{3}^{-}-\mathrm{N}, 0.044-0.549 \mathrm{mg} / \mathrm{L},(0.16 \mathrm{mg} / \mathrm{L}$ on the average ); and the mean TP was $0.103 \mathrm{mg} / \mathrm{L}$. Compared with the results of earlier investigations, TN, TP and $\mathrm{NH}_{4}^{+}-\mathrm{N}$ had increased, $\mathrm{COD}_{\mathrm{Mn}}$ had slightly decreased. At present, the water quality was bad, but different sites exhibited different conditions. The water quality in the center of lake was the best. As a whole, East Lake Taihu was meso-eutrophic. Some part of the lake was eutrophic. To improve the water quality of East Lake Taihu, it is important to shut off the external pollution sources, ensure the function of East Lake Taihu, control the scale of pen-culture and recover and protect the aquatic vegetation.

Keywords: Water quality; environmental protection; East Lake Taihu

东太湖位于太湖东南隅, 地理位置北纬 $30^{\circ} 58^{\prime}-31^{\circ} 07^{\prime}$, 东径 $120^{\circ} 25^{\prime}-120^{\circ} 35^{\prime}$, 与太湖主体以狭窄的 湖面相通, 总长度 $27.5 \mathrm{~km}$, 最大宽度 $9.0 \mathrm{~km}$, 总面积 $131 \mathrm{~km}^{2}$, 平均水深 $0.9 \mathrm{~m}$, 最大水深 $1.3 \mathrm{~m}$, 蓄水量 1.18 $\times 10^{8} \mathrm{~m}^{3}$, 是长江中下游地区较典型的草型湖泊 ${ }^{[1]}$. 东太湖是上海的重要水源供给地, 其来水占到上海水资 源供应量的 $16.9 \%$. 2 . 东太湖又是太湖的主要泻水通道, 平均换水周期只有 $10 \mathrm{~d}^{[3]}$, 来自西太湖的水流所 携带的大量营养物质, 为东太湖渔业发展提供了优越条件, 太湖养殖业总产值的 $57.2 \%$ 来自于东太湖 ${ }^{[4]}$. 近年来, 随着湖区养殖业的不断发展, 东太湖的水环境问题引起了人们的更多关注 ${ }^{[5-8]}$. 为更好地了解东

* 中国科学院农业项目 ( NK - C - 03)、国家“863”重大科技专项( 2002AA601011-04-02)和江苏省自然科学基金 ( BK2002148 )联合资助. 2005-05-29 收稿,2005-07-29 收修改稿. 白秀玲,女, 1980 年生, 硕士; E-mail : xlbai@ niglas. ac. cn.

**通讯作者:谷孝鸿;E-mail:xhgu@ niglas. ac.cn. 
太湖的水环境特征及其变化情况,我们从东太湖不同类型水域区选取了 6 个点,进行了为期一周年的监测, 旨在探讨东太湖水环境演变特征,为东太湖水环境的合理治理与保护提供参考依据.

\section{1 研究方法}

\section{1 采样点的布置}

根据东太湖功能及不同利用方式的区域,于 2002 年 4 月在东太湖布设了六个采样点( 图 1 ). 1 号点位 于西太湖南部主体与东太湖交界处,水生植被生长较好,但受西太湖来水影响较大. 2 号点在东大圩外的一 个水草堆积场附近. 3 号点位于东太湖南岸西端的太浦河口, 受上游来水影响较大. 4 号点处于东太湖开阔 水域的中部, 四周为多重养殖围网环抱,但水生植物生长较好. 5 号点位于东太湖北岸中部的一条河道口附 近,受工业和农业污水污染较重. 6 号点位于东太湖北部.

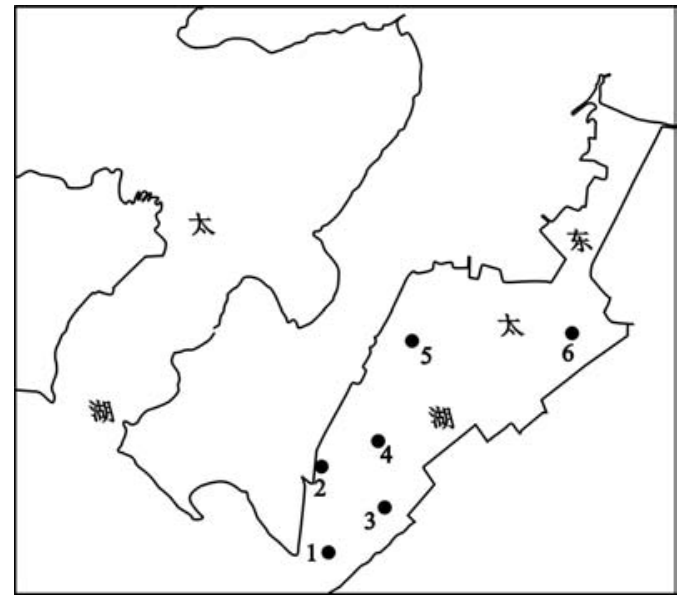

图 1 东太湖采样点分布

Fig. 1 Sampling sites in East Lake Taihu

\section{2 样品采集和水环境测定参数}

从 2002 年 4 月至 2003 年 4 月共 13 个月,逐月采 集表底层混合水样进行理化分析. 测定参数有: 水深 $(\mathrm{h})$ 、水温 $(\mathrm{t})$ 、透明度 $(\mathrm{SD})$ 、悬移质 $(\mathrm{SS})$ 、氨氮 $\left(\mathrm{NH}_{4}^{+}-\right.$ $\mathrm{N})$ 、硝态氮 $\left(\mathrm{NO}_{3}-\mathrm{N}\right)$ 、亚硝态氮 $\left(\mathrm{NO}_{2}-\mathrm{N}\right)$ 、总氮 ( TN )、总磷( TP )、溶解态总氮 ( DTN )、溶解态总磷 ( DTP )、叶绿素( Chl. a )、化学耗氧量 $\left(\mathrm{COD}_{\mathrm{Mn}}\right)$. 测定按 湖泊富营养调查规范 ${ }^{[6]}$ 方法进行.

\section{2 结果与分析}

\section{1 东太湖水环境指标的变化特征}

2.1.1 东太湖水环境主要物理因子的变化特征(表 1 ) 东太湖月平均水温最高出现在 8 月, 为 $30.8^{\circ} \mathrm{C}$, 最低 出现在 12 月, 为 $3.3^{\circ} \mathrm{C}$. 水体透明度平均为 $98.7 \mathrm{~cm}$. 根据东太湖透明度与平均水深比值来看, 透明度可占 平均水深的 $61.0 \%$, 据 $1991-1994$ 年的调查数据 知 $^{[9]}$, 东太湖的透明度平均值是 $71 \mathrm{~cm}$, 水深平均值 $112 \mathrm{~cm}$, 透明度占到了平均水深的 $63.4 \%$,与 2002 年透 明度占水深的 $61.0 \%$ 相比,变化不明显. 若补偿深度按透明度的 2 倍计,则有相当强的太阳光线可透射到 湖底层, 这为底层水生植物的生长发育提供了充足的光源. 东太湖水体中 SS 浓度相对较低, 但高水温期 与低水温期水体 SS 浓度差异显著. 10-12 月期间, SS 的平均浓度为 $9.68 \mathrm{mg} / \mathrm{L} ; 1-4$ 月期间, $\mathrm{SS}$ 的平均浓 度为 $23.41 \mathrm{mg} / \mathrm{L} . \mathrm{SS}$ 的变化特征与水生高等植物的生长明显相关 ${ }^{[10]}$. 高水温期间, 高等水生植物生命活 动旺盛,水体中颗粒物质被水生植物吸附、截留等而沉降除去,悬移质浓度因而降低; 低水温期间,高等水生 植物生命活动停滞, 有的种群死亡, 水生植物叶片吸收水体中颗粒物的能力降低; 另一方面, 由于高等水生 植物在低水温期间种群密度下降, 使得水土界面沉积物再悬浮能力加强, 悬移质浓度也随之升高 ${ }^{[1,12]}$.

表 1 东太湖水环境主要物理因子的变化特征

Tab. 1 The variation of physical parameter in East Lake Taihu

\begin{tabular}{ccccc}
\hline 变量 & 温度 $\left({ }^{\circ} \mathrm{C}\right)$ & 透明度 $(\mathrm{cm})$ & 水深 $(\mathrm{cm})$ & 悬移质 $(\mathrm{mg} / \mathrm{L})$ \\
\hline 变幅 & $3.3-30.8$ & $70.5-135.8$ & $130.4-211.0$ & $4.95-33.88$ \\
平均值 & 17.3 & 98.7 & 162.1 & 19.88 \\
\hline
\end{tabular}

2.1 .2 主要化学因子的变化特征 氮化合物的变化趋势如图 $2 \mathrm{~A} 、 2 \mathrm{~B} .2002$ 年 TN 的变化范围 $0.57-3.91$ $\mathrm{mg} / \mathrm{L}$, 平均值 $1.61 \mathrm{mg} / \mathrm{L} . \mathrm{NH}_{4}^{+}-\mathrm{N}$ 的变化范围 $0.01-0.42 \mathrm{mg} / \mathrm{L}$, 平均值 $0.14 \mathrm{mg} / \mathrm{L} . \mathrm{NO}_{3}^{-}-\mathrm{N}$ 变化范围是 
$0.044-0.549 \mathrm{mg} / \mathrm{L}$, 平均值 $0.16 \mathrm{mg} / \mathrm{L} . \mathrm{TN} 、 \mathrm{DTN}$ 与 $\mathrm{NO}_{3}^{-}-\mathrm{N}$ 具有相似的变化特征. 东太湖水体 TN、DTN 浓度峰值在春季 3-4 月, 比 $\mathrm{NO}_{3}^{-}-\mathrm{N}$ 变化曲线的峰值在时间上约滞后 1 个月. 这一结论与 $1991-1994$ 年 对东太湖的研究结果一致 ${ }^{[9]}$. 同时, TN 与 DTN 变化趋势基本一致,每月测定水体中 DTN 的平均浓度均占 $\mathrm{TN}$ 浓度的 $80 \%$ 以上, 表明东太湖水体中各类 $\mathrm{N}$ 化合物主要以溶解态的形式存在, 在颗粒物中的赋存量很 少. 东太湖水体 $\mathrm{NH}_{4}^{+}-\mathrm{N}$ 浓度从春季 4 月逐步增高, 至 7 月份达到最高值 $0.336 \mathrm{mg} / \mathrm{L}$ 之后, $\mathrm{NH}_{4}^{+}-\mathrm{N}$ 浓度 便转而稳步下降, 直至翌年的 3 月份达到 $0.019 \mathrm{mg} / \mathrm{L}$ 的最低值. $\mathrm{NO}_{2}^{-}-\mathrm{N}$ 浓度除个别月外, 基本上在 0.015 $\mathrm{mg} / \mathrm{L}$ 上下波动, 由于 $\mathrm{NO}_{2}^{-}-\mathrm{N}$ 价态的不稳定性, 常存在于还原性环境中. 东太湖水体全年均能测定出 $\mathrm{NO}_{2}^{-}-\mathrm{N}$, 这与水体中有大量有机物质及还原性物质有关. 东太湖水体中 $\mathrm{COD}_{\mathrm{Mn}}$ 的平均值为 $4.23 \mathrm{mg} / \mathrm{L}$. 最 大值出现在 2002 年的 6 月, 为 $5.96 \mathrm{mg} / \mathrm{L}$. 而最小值出现在 2002 年的 5 月, 为 $3.29 \mathrm{mg} / \mathrm{L}$, 表明东太湖 $\mathrm{COD}_{\mathrm{Mn}}$ 年内变化不明显. Chl. a 的变化有明显的双峰型特征, 在生长期内, Chl. a 浓度由 4 月份的 $2.11 \mu \mathrm{g} / \mathrm{L}$ 逐步升高至 8 月份的 $6.57 \mu \mathrm{g} / \mathrm{L}$, 达到该年度第 1 个 $\mathrm{Chl} . \mathrm{a}$ 的峰值; 从 9 月份开始, 水体中 $\mathrm{Chl} . \mathrm{a}$ 的浓度逐步 下降, 12 月份下降至最低值, 而后在翌年的 $1-3$ 月, 东太湖水体中 Chl. a 的浓度又稳步上升, 在 3 月份达到 第 2 个峰的峰值 (图 2c ). TP 和 DTP 的年变化曲线如图 2D. 东太湖水体中 TP 浓度较低, 平均值 $0.103 \mathrm{mg} /$ $\mathrm{L}$, 最大值 $0.187 \mathrm{mg} / \mathrm{L}$, 最小值 $0.051 \mathrm{mg} / \mathrm{L}$. DTP 的浓度则更低, 平均值 $0.064 \mathrm{mg} / \mathrm{L}$, 最大值 $0.128 \mathrm{mg} / \mathrm{L}$, 最 小值 $0.004 \mathrm{mg} / \mathrm{L}, \mathrm{DTP}$ 的浓度约占 TP 浓度的 $60 \%, \mathrm{TP}$ 和 DTP 的变化趋势基本一致.

\section{2 东太湖水质综合评价}

为综合反映东太湖水质状况, 从生态系统中选择了 $\mathrm{COD}_{\mathrm{Mn}} 、 \mathrm{TN} 、 \mathrm{TP} 、 \mathrm{SD} 、 \mathrm{Chl} . \mathrm{a} 、 \mathrm{SS}$ 作为评价参数, 采用相 崎守弘关于评价湖泊富营养化程度的评分法 ${ }^{[6]}$, 参考太湖富营养化程度评价标准 ${ }^{[6]}$, 对东太湖各点和全东 太湖的营养状态进行了综合评价( 表 2 ). 各个点位的营养参数值采用 2002 年 4 月 -2003 年 4 月的年均值, 东太湖的营养参数值是采用各个点位年平均值. 从评价结果可以看出, 东太湖目前处于中富营养状态, 其 中 3 号点和 5 号点已处于富营养状态, 湖心区 4 号点营养状态指数最低. 5 号点位于东太湖北岸中部的一 条河道口附近, 东山镇的部分工业及生活污水经该河道排人太湖中, 过往船只对水环境的扰动很大. 3 号点 位于太浦河口处,自 2002 年 1 月 30 日至 4 月 4 日的“引江济太”工程中, 供引 $9 \times 10^{8} \mathrm{~m}^{3}$ 长江水人太湖, 其 中有 $6 \times 10^{8} \mathrm{~m}^{3}$ 水通过太浦河流向下游 ${ }^{[13]}$, 该点受来水带来营养物质的影响, TN、TP 明显高于东太湖的平 均值. 2 号点附近为养殖废草堆积场, 水草腐烂分解和水体下泄带来的有机物较多, 有机污染比较严重. 1 号和 4 号点水体营养盐含量基本上都低于东太湖的平均值, 表明该区域的水质较好, 这与水生植物的大量 生长有关. 总之, 东太湖的不同区域, 由于受局部小环境的影响,水质有明显的差别.

表 2 东太湖及各样点营养状态综合评价结果( $2002-2003)$

Tab. 2 Results from comprehensive evaluation for trophic states of each sampling site and the whole East Lake Taihu

\begin{tabular}{ccccccccc}
\hline 采样点 & $\mathrm{COD}_{\mathrm{Mn}}$ & $\mathrm{TN}$ & $\mathrm{TP}$ & $\mathrm{SD}$ & Chl. a & $\mathrm{SS}$ & 平均值 & 营养状态 \\
\hline 1 & 60.0 & 73.8 & 69.4 & 65.2 & 34.2 & 66.4 & 61.5 & 中 - 富 \\
2 & 66.0 & 73.7 & 65.9 & 62.6 & 41.8 & 60.8 & 61.8 & 中 - 富 \\
3 & 60.5 & 78.6 & 72.7 & 70.1 & 39.1 & 76.3 & 66.2 & 富 \\
4 & 61.7 & 66.1 & 66.4 & 61.8 & 34.9 & 60.6 & 58.6 & 中 - 富 \\
5 & 64.0 & 78.5 & 72.7 & 67.6 & 47.6 & 79.4 & 68.3 & 富 \\
6 & 65.7 & 71.6 & 67.6 & 66.2 & 43.0 & 69.4 & 63.9 & 中富 \\
东太湖 & 63.2 & 74.3 & 69.4 & 65.4 & 41.1 & 71.1 & 64.1 & 中富 \\
\hline
\end{tabular}



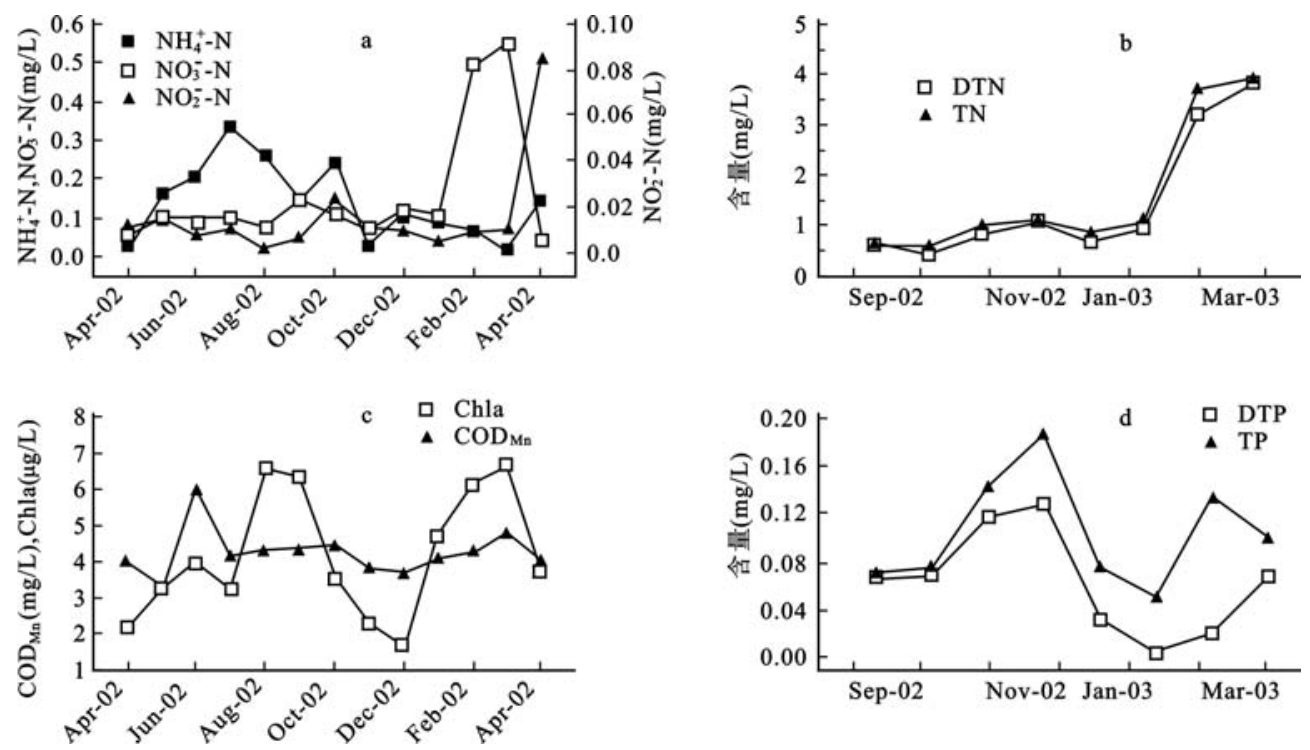

图 22002 年东太湖营养盐指标年内变化

Fig. 2 change of nutrition indexes in East Lake Taihu in 2002 ( a: $\mathrm{NH}_{4}^{+}-\mathrm{N} 、 \mathrm{NO}_{3}^{-}-\mathrm{N} 、 \mathrm{NO}_{2}^{-}-\mathrm{N} ; \mathrm{b}: \mathrm{TN} 、$ DTN ; $\mathrm{c}: \mathrm{Chla} 、 \mathrm{COD}_{\mathrm{Mn}} ; \mathrm{d}: \mathrm{TP} 、$ DTP )

\section{3 东太湖水质的变化趋势及原因分析}

从 1960 年 6 月到 $2000-2002$ 年东太湖水质调查结果知, TN 、TP 和 $\mathrm{NH}_{4}^{+}-\mathrm{N}$ 均明显增加, $\mathrm{COD}_{\mathrm{Mn}}$ 有所

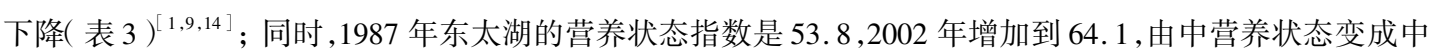
富营养状态 ${ }^{[9,14]}$ ( 图 3 ). 东太湖属于高密度围网养殖湖区, 其网围养殖始于 1984 年, 总面积从最初的 266

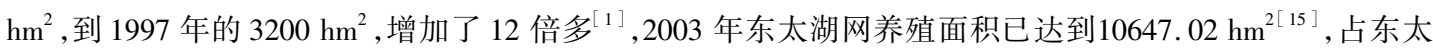
湖总水面的比例高达 $79.25 \%$. 纵横交错的围网几乎覆盖了整个东太湖的水面,因而东太湖水质的变化与 网围养殖面积和种类的变化有着密切的关系. 60 年代以前对东太湖人为干预较少, 水生植物大多自生自 灭,腐烂分解后剩余部分沉入湖底, 同时外源污染物在东太湖被水草吸收、过滤而沉积, 而随水流出的污染 物较少, 造成了 60 年代初 $\mathrm{COD}_{\mathrm{Mn}}$ 值较高 ${ }^{[9]}$. 80 年代以后, 东太湖围网养殖面积迅速增加, 湖内大量的沉水 植物被刚割用于湖内围网养殖, 还有一部分投放到湖外鱼池, 水生植物得到充分利用, 减少其在湖内积累, 故湖水 $\mathrm{COD}_{\mathrm{Mn}}$ 有所降低. 湖内围网养殖饵料的投放增加了水体中的营养盐, 同时围网使得湖水水体流速减 慢, 水体的环境容量减小, 从而造成水质恶化. 根据饵料和苗种中所含氮磷与输出水产品所含氮磷的差, 知 每生产 $1 \mathrm{t}$ 鱼向湖内释放氮 $141.25 \mathrm{~kg}$, 磷 $14.14 \mathrm{~kg}$, 每生产 $1 \mathrm{t}$ 螃蟹向湖内释放氮 $517.81 \mathrm{t}$, 磷 $71.57 \mathrm{~kg}^{[16]}$. 养 鱼区的总氮和氨氮分别比网外高 $228 \%$ 和 $37 \%$, 比对照区高 $219 \%$ 和 $300 \%$, 网围养殖区的 TP 比对照区高 对照区高 $162 \%$, 同时发现网围养鱼区的水色比水草种植区和网外高, 在鱼类生长旺盛期水色更差 ${ }^{[7-19]}$. 网围养殖也促使表层沉积物的营养盐发生变化, 自 1980 年之后的 11 年, TN 和 TOC 分别增长了 0.83 和 5.93 倍 ${ }^{[16]}$, 等于增加了湖体的内源污染源. 东太湖是典型的草型湖泊, 水生植被覆盖率达 $95 \%{ }^{[2]}$. 随着水 生植物种群密度和生物量的增加, 水生植被的光合作用促使植物体不断地从水体和沉积物中吸收大量的营 养盐, 水生植物对营养物质的吸收和改善水环境的生态功能得到充分发挥 ${ }^{[20]}$, 减缓了东太湖水体恶化的进 程. 1 号点水生植被生长旺盛, 营养指标大多低于东太湖的平均值, 水质相对较好; 同时由于湖湾四周稳定 生长的水生植被的生物净化保护, 使 4 号点的营养指标较低, 这也表明该区域水质较好. 但过度围网养殖 
造成静水环境, 阻碍了污染物的稀释和扩散, 引起围网区内水生植被的严重退化, 使得利用价值极低的浮叶 植物、漂浮植物及丝状藻类( 水绵) 蔓延滋生. 湖区内无秩序的围网也阻碍刈割水草, 使湖体内部营养盐不 能及时转移出去 ${ }^{[16,21]}$.

表 3 东太湖部分营养盐指标的变化

Tab. 3 The change of nutrition indexes in East LakeTaihu

\begin{tabular}{ccccccccc}
\hline 年份 & 1960 & 1980 & $1987-1988$ & 1991 & 1993 & 1997 & 1999 & $2000-2002$ \\
\hline $\mathrm{COD}_{\mathrm{Mn}}(\mathrm{mg} / \mathrm{L})$ & $6.0-16.0$ & 2.87 & 2.88 & 5.5 & 5.57 & 5.51 & 4.56 & 3.76 \\
$\mathrm{TN}(\mathrm{mg} / \mathrm{L})$ & & 0.65 & 1.72 & 1.01 & 1.04 & 1.39 & 1.63 & 1.08 \\
$\mathrm{TP}(\mathrm{mg} / \mathrm{L})$ & & 0.03 & 0.063 & 0.043 & 0.075 & 0.031 & 0.095 & 0.07 \\
$\mathrm{NH}_{4}^{+}-\mathrm{N}(\mathrm{mg} / \mathrm{L})$ & $<0.04$ & 0.05 & & 0.14 & 0.2 & 0.19 & 0.25 & 0.07 \\
\hline
\end{tabular}

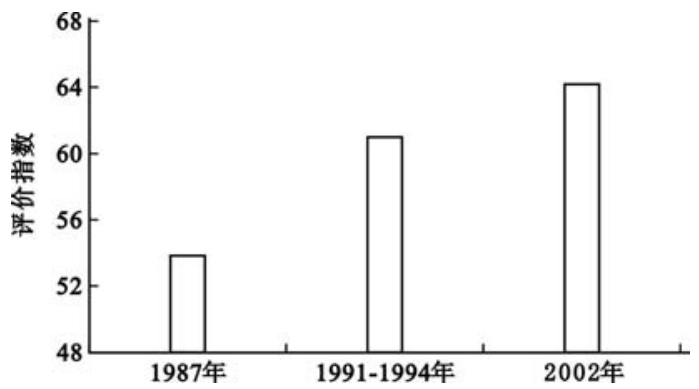

图 3 东太湖营养状态指数变化趋势

Fig. 3 The change of trophic states index in East Lake Taihu

东太湖水环境的变化,驱动因素有内源性和外源性、生物因素和非生物因素、自然因素和人为因素 ${ }^{[22]}$. 根据 1999 年调查数据, 计算出东太湖污染负荷的贡献率, 湖泊内部自身的养殖污染占总污染物 N,P 分别为 $8.35 \%$ 和 $20.07 \%$, 面源污染占 $91.65 \%$ 和 $79.93 \%$. 23$]$. 由此可见,切断或减少外源污染物的输人对东太湖 尤为重要,也是控制东太湖污染的关键. 2000 年太湖流域点源污染治理的 “零点行动” 对减轻太湖及流域 水质的污染具有积极的作用 ${ }^{[24]}$.

\section{4 建议}

(1)从东太湖实际状况出发,制定出合理的生态规划, 明确其功能分区, 严格控制养殖规模. 实现渔业 资源的可持续利用. 同时恢复和加强对水生植被的保护, 促进湖泊生物多样性,恢复良性生态. 东太湖大面 积的水生植被对保护水环境起到了积极作用,一方面有效地吸收水中营养盐, 促进东太湖的营养盐输出, 另 一方面高、低等植物的相生相克, 大量高等植物的生长有效地抑制藻类的过量生长, 同时水生植物固着底泥 和水体悬浮物能使水体变清有利于生物多样性发展, 实现浅水湖泊的生态逆转和良性循环.

( 2 ) 要严格控制工农业废水和生活污水等外源污染物的排人. 东太湖处在经济发达的长三角, 人口密 集,乡镇企业、旅游业和农业对周围水域的污染不容忽视.

\section{5 参考文献}

[1] 谷孝鸿, 王晓蓉,胡维平. 东太湖渔业发展对水环境的影响及其生态对策. 上海环境科学, 2003,22 ( 10$): 702-704$. 
[2] 陈荷生. 东太湖水环境保护迫在眉睫. 水资源保护,2000,61( 3):17 - 20 .

[3] 杨清心, 李文朝. 太湖藻类水华盛发期水质富营养化状况的 Fuzzy 聚类分析. 南京林业大学学报( 生 态专集 ),1991,15(增刊 ): $121-127$.

[4] 杨再福,施炜刚,陈立侨等. 东太湖生态环境演变与对策. 中国环境科学, 2003,23( 1):64-68.

[5] 中国科学院南京地理研究所. 太湖综合调查初步报告. 北京:科学出版社, 1965:35-41.

[6] 金相灿主编. 中国湖泊富营养化. 北京: 中国环境科学出版社, 1990:185-194.

[7] 孙顺才, 黄渏平主编. 太湖. 北京: 海洋出版社,1993.

[8] 石建华. 东太湖的环境质量现状调查评价. 湖泊科学,1994,6( 2):166-170.

[9]陈开宁,范成新,季 江. 东太湖水环境质量调查及保护对策. 海洋湖沼通报,1996( 1):9-17.

[10]戴 䒭,倪乐意,谢 平等. 利用大型围隔研究沉水植被对水体富营养化的影响. 水生生物学报, $1999,23(2): 97-101$.

[11] 邱东茹, 吴振斌, 刘保元等. 武汉东湖水生植物生态学研究一一I. 后湖水生植被动态与水体性质. 武汉植物学研究,1997,15( 2 ): $123-130$.

[12] 杨清心. 东太湖水生植被的生态功能及调节机制. 湖泊科学, 1998,10( 1 ):67 -72.

[13 ] 张文斌. “引江济太”对无锡水环境利弊析. 江苏水利, 2002,12:19-20.

[14] 孙顺才,黄渏平主编. 太湖. 北京:海洋出版社, 1993:252.

[15] 杨英宝, 江 南, 殷立琼等. 东太湖湖泊面积及围网养殖动态变化的遥感监测. 湖泊科学, 2005, 17 ( 2 ): $133-138$.

[16] 杨清心,李文朝. 东太湖围网养鱼后生态环境的演变. 中国环境科学,1996,16( 2):101 - 106 .

[17] 吴庆龙. 东太湖渔业养殖可持续发展的思考. 湖泊科学, 2001,13(4):337 - 343.

[ 18 ] 吴庆龙,陈开宁, 胡耀辉. 东太湖河蟹围网养殖的环境效应. 农业生态环境, 2001,20(6):432 -434.

[19] 吴庆龙. 东太湖艾草区网围养鱼模式试验研究. 海洋湖沼通报, 1997,( 1):38 - 42.

[20] 谷孝鸿, 陈开宁, 胡耀辉. 东太湖伊乐藻的营养繁殖及对渔业污水的净化. 上海环境科学, 2002, 21 ( 1 ):43-45.

[21] 杨清心, 李文朝,俞 林等. 东太湖围栏养殖及其环境效应. 湖泊科学, 1995,7( 3$): 256-262$.

[22] 李文朝. 浅水湖泊生态系统的多稳态理论及其应用. 湖泊科学, 1997,9( 2 ):104.

[23] 谷孝鸿, 胡维平, 胡耀辉等. 人类活动对浅水湖泊的影响一以东太湖为例. 河海大学学报( 自然科 学版),2004,32( 7 ):142-146.

[24] 黄文钰,杨桂山. 太湖流域“零点”行动的环境效应. 湖泊科学,2002,14( 1 ):67-71. 